
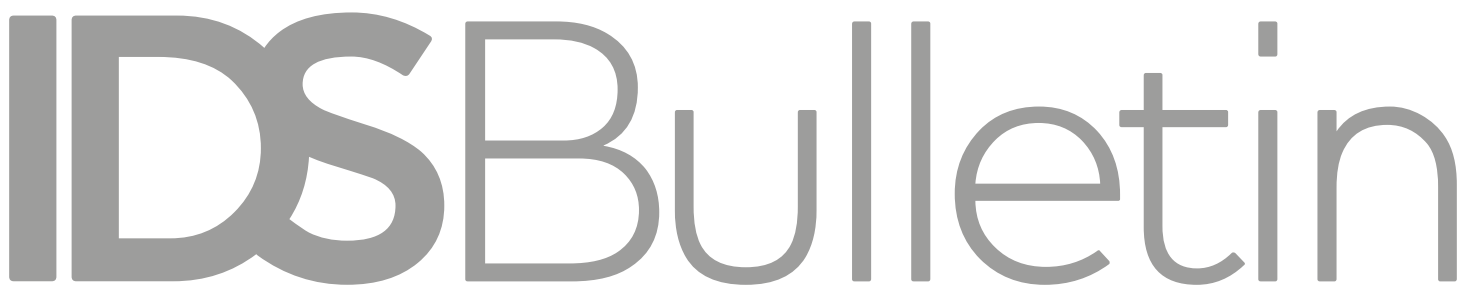

Transforming

Development Knouledge

Volume 50 | Number 1 | May 2019

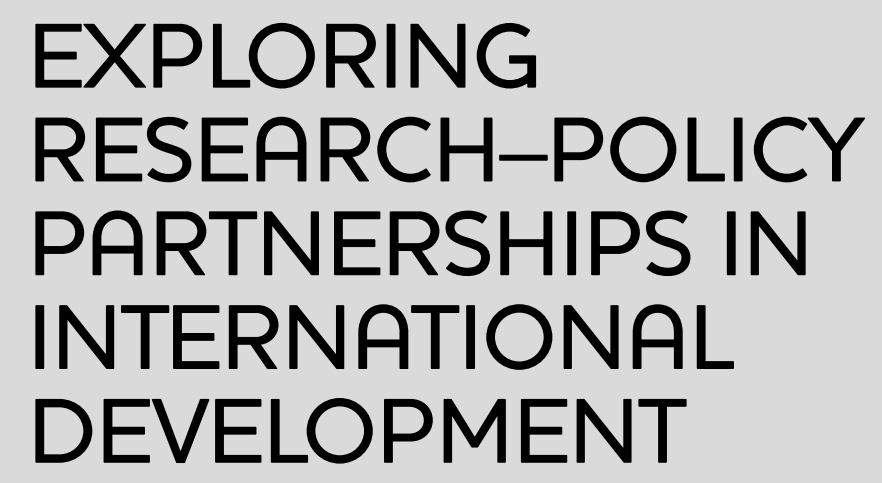

Editors James Georgalakis and Pauline Rose

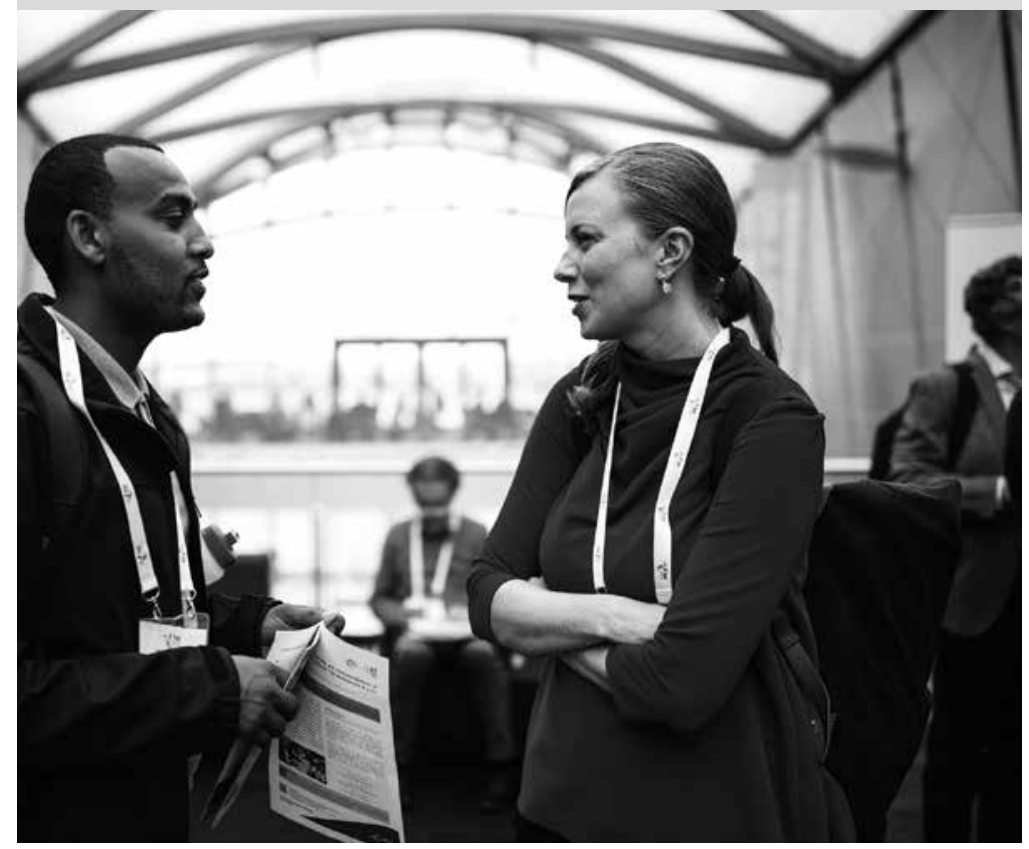


Notes on Contributors

Foreword

Diana Dalton

Introduction: Identifying the Qualities of Research-Policy Partnerships in International Development - A New Analytical Framework

James Georgalakis and Pauline Rose

\section{Rethinking Research Impact through Principles for Fair and Equitable Partnerships}

Pathways to Impact: Insights from Research Partnerships in Uganda and India Rachel Hinton, Rona Bronwin and Laura Savage

Exploring Partnerships between Academia and Disabled Persons' Organisations: Lessons Learned from Collaborative Research in Africa

Maria Kett, Mark T. Carew, John-Bosco Asiimwe, Richard Bwalya, Anderson Gitonga, Boakai A. Nyehn, Joyce Olenja, Leslie Swartz and Nora Groce

Layered and Linking Research Partnerships: Learning from YOUR World Research in Ethiopia and Nepal

Vicky Johnson, Anannia Admassu, Andrew Church, Jill Healey and Sujeeta Mathema

Fundamental Challenges in Academic-Government Partnership in Conflict Research in the Pastoral Lowlands of Ethiopia

Mercy Fekadu Mulugeta, Fana Gebresenbet, Yonas Tariku and Ekal Nettir

Regional Research-Policy Partnerships for Health Equity and Inclusive Development: Reflections on Opportunities and Challenges from a Southern African Perspective

Nicola Yeates, Themba Moeti and Mubita Luwabelwa

How Did Research Partnerships Contribute to Bangladesh's Progress in Improving Lives?

Mushtaque Chowdhury

Glossary 


\title{
Rethinking Research Impact through Principles for Fair and Equitable Partnerships" ${ }^{+}$
}

\author{
Kate Newman, ${ }^{1}$ Sowmyaa Bharadwaj ${ }^{2}$ and \\ Jude Fransman ${ }^{3,4}$
}

\begin{abstract}
With renewed investment of the UK's official development assistance (ODA) commitment into research, there is a need to rethink traditional understandings of 'research impact'. In this article, we argue that impact in ODA-funded research should go beyond translating research findings into practice and policy or implementing research in partnership with research mediators/users. Instead, development agendas of those living and working in the global South, including academics and practitioners, and those working in international non-governmental organisations should influence the research agendas, approaches, and schemes that allocate funding. These stakeholders have profound knowledge of what real-world impact looks like, the types of impact needed, local and national realities, and how complex processes of development impact unfold. Drawing on a programme of research conducted by the Rethinking Research Collaborative, we examine eight principles for 'fair and equitable research partnerships' using insights from our individual experiences to offer new thinking on ODA-funded research impact.
\end{abstract}

Keywords: research impact, research partnerships, official development assistance (ODA), Global Challenges Research Fund (GCRF), INGOs, global South, practitioners, academics, multiple knowledges.

\section{Introduction}

The ESRC-DFID-funded Joint Fund for Poverty Alleviation Research and the Raising Learning Outcomes in Education Systems Programme are examples of an accelerating investment of the UK's official development assistance (ODA) into research, culminating in the launch of the $£ 1.5$ billion Global Challenges Research Fund (GCRF) in 2015. This unprecedented investment responds to persuasive arguments for the benefits of academic knowledge to global development (e.g. Conway and Waage 2010; Bardsley 2017). Allocating ODA to research also suggests that research can be 'ODA compliant'; i.e. that it can have the promotion of the economic development and welfare of developing 
countries as its main objective. ${ }^{5}$ As such, any research funded through the GCRF must:

Seek to investigate a specific problem or seek a specific outcome which will have an impact on a developing country or countries;

- Provide evidence as to why this is a problem for the developing country or countries;

Address the issue identified effectively and efficiently;

Use the strengths of the UK to address the issue, working in collaboration with others as appropriate;

Demonstrate that the research is of an internationally excellent standard;

- Identify appropriate pathways to impact to ensure that the developing country benefits from the research. ${ }^{6}$

These criteria imply that research must not only be problem (or solution) focused, relating to the 'real-world issues' and contexts of developing countries. It must also be clear from the onset about how it will create impact, in relation to economic development and the welfare of countries on the Development Assistance Committee (DAC) list (DFID 2016). Although how impact is understood in this context is not clarified.

Research impact has been an increasing priority in the UK since the focus of Tony Blair's government on evidence-informed policy in the late 1990s (Nesta/Alliance for Useful Evidence 2016) and the continuing 'impact agenda' for higher education, channelled through the Research Excellence Framework (REF) (HEFCE 2011: 17, 2017; Nurse 2015). The emphasis has shifted somewhat away from communication of research outputs to engaging users and mediators in research processes (see Fransman 2018). However, despite new requirements to describe 'pathways to impact' in order to secure public research funding, the focus remains on a relatively simplistic supply-side model of impact (Boswell and Smith 2017) which positions the expertise in academia and tends to attribute impact to the individual academic (Dunlop 2018); rather than recognising the complexity of systems and the difficulties of separating the effect of individual action from systemic effects (Cairney and Oliver 2018).

At the same time, those working as practitioners or policymakers in the international development sector engage with the complexity of 'creating impact' on a daily basis, and acknowledge that impact is dependent on a range of factors and actors (Datta 2012; Green 2016). Whether and how outcomes are achieved not only depends on an organisation's knowledge, skills, and expertise in programme design and delivery, but also on more difficult-to-control issues such as timing, political expediency, individual personalities, and relationships. 
For activities to contribute to impact depends on deep contextual understandings, well-developed theories of change (which make the link between vision, outcomes, activities and assumptions) and buy-in from a range of individuals and groups. Such practices also operate within (and are therefore constrained by) national and international policy systems (see Carbonnier and Kontinen 2014; Kok et al. 2017).

The ability of any development activity to create impact is therefore complex and social - it involves an array of actors and implies the importance of a collaborative approach (Georgalakis 2017). In this article, we argue that for ODA-funded research to contribute to realworld impact, we need to ground that research in the experience and current practice of development practitioners, and their knowledge and understanding of what impact is needed and how this might be created. This suggests the need to radically rethink our assumptions in this area. This means that rather than starting with research priorities and the implications of the research design for 'pathways to impact', we need to take the ongoing development activities of practitioners as a starting point, working with, and within, their wider processes of change. This rethinking has implications for how research is understood in relation to other knowledge systems, how research funding is allocated, and how research collaborations are designed, implemented, and supported.

This need to rethink what is understood by (international development) research impact, and how that impact is created is a key concern of the Rethinking Research Collaborative (RRC). The collaborative (which was established in 2018) is an informal international network of academics, civil society organisations (CSOs), social movements, international non-governmental organisations (INGOs), and research support providers, who are working together to encourage more inclusive, responsive, and transformative collaborations for useful and accessible international development research. While the focus of the collaborative is on international development and ODA-funded research, it also interacts with a growing body of literature on 'knowledge mobilisation', 'evidence use'; 'co-production', and 'joint inquiry' (see, for example, Beckett et al. 2018; Oliver and Boaz forthcoming, 2019; Prainsack 2018). However, while there is a growing consensus around the importance of collaborative approaches for genuinely impactful research, there remains a tendency to foreground the research sphere in this work (focusing on improving the participation of non-academic stakeholders in research processes; see, for example, Fransman and Newman forthcoming), rather than foregrounding the sphere of development practice (and asking how research can be conceived and developed in this applied space).

In this article, we (three RRC representatives - from Christian Aid, the Open University, and Praxis Institute of Participatory Practices) briefly introduce current thinking on research impact, and then share the findings of a recent programme of strategic research carried out by the RRC. This research led to the generation of eight principles for fair and equitable research partnerships. We consider each principle 
Figure 1 Linear model of research impact

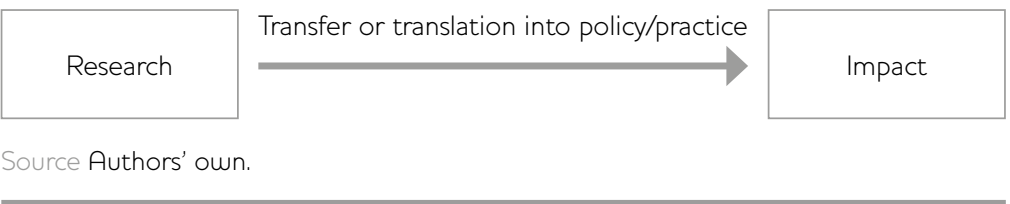

in turn, drawing on examples from our own experience to suggest that to operationalise the principles it is necessary to reconsider how research impact is understood. We conclude by proposing that if fair and equitable research partnerships are to have impact on poverty, in line with ODA criteria, then a renewed model of ODA-funded research is needed. Such a model involves changing and strengthening research systems (as well as institutions) both in the global North and South.

\section{Models of research impact and the implications for research collaboration}

The current drive in UK higher education policy to focus on research impact (as an end goal) and research collaboration (as a means to that goal) encompasses a range of traditions, approaches, and understandings that have emerged from sectors as diverse as health and social care, cultural heritage and community development, and science and technology (see Fransman 2018). A review of the literature and practice across these different sectors suggests that understandings of research impact have tended to evolve in similar ways which we have captured through four models; represented diagrammatically in Figures 1-4. Initially, impact was understood through simplistic linear models of knowledge transfer (see Figure 1).

These evolved to place greater emphasis on dialogue, engagement, or collaboration (see Figure 2) while retaining the linear relationship between spheres of research (which involves varying degrees of participation) and the sphere of impact.

A third wave of models began to recognise research impact as part of a more cyclical process of knowledge production and policymaking (see

Figure 2 Relationship model of research impact

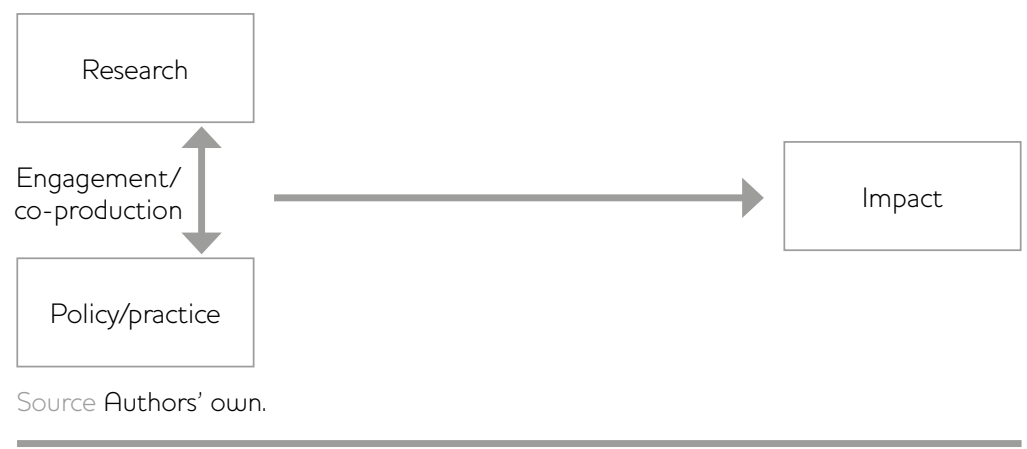


Figure 3 Cyclical systems model of research impact

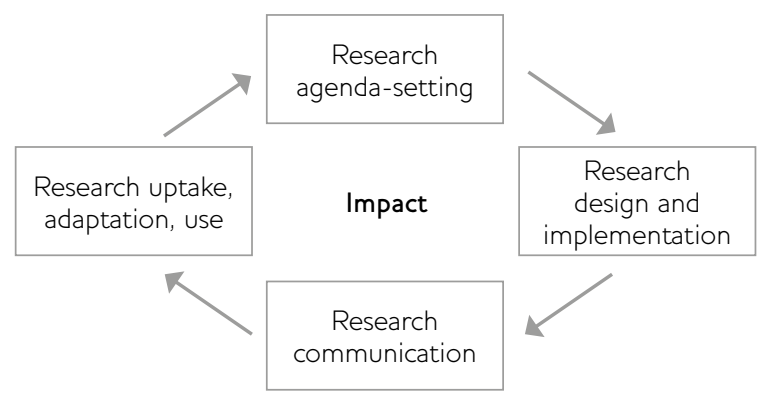

Source Authors' own.

Figure 3). While 'impact' is located in the sphere of uptake/adaptation/ use, the nature of these complex processes will be affected by the ways in which research agendas have been set and the nature of research production and communication.

More recently, understandings of impact evolved to recognise impact as part of more complex systems of knowledge mobilisation (see Figure 4).

These different models have implications for the way research impact is understood, the types of collaboration that are involved, and how capacity is strengthened.

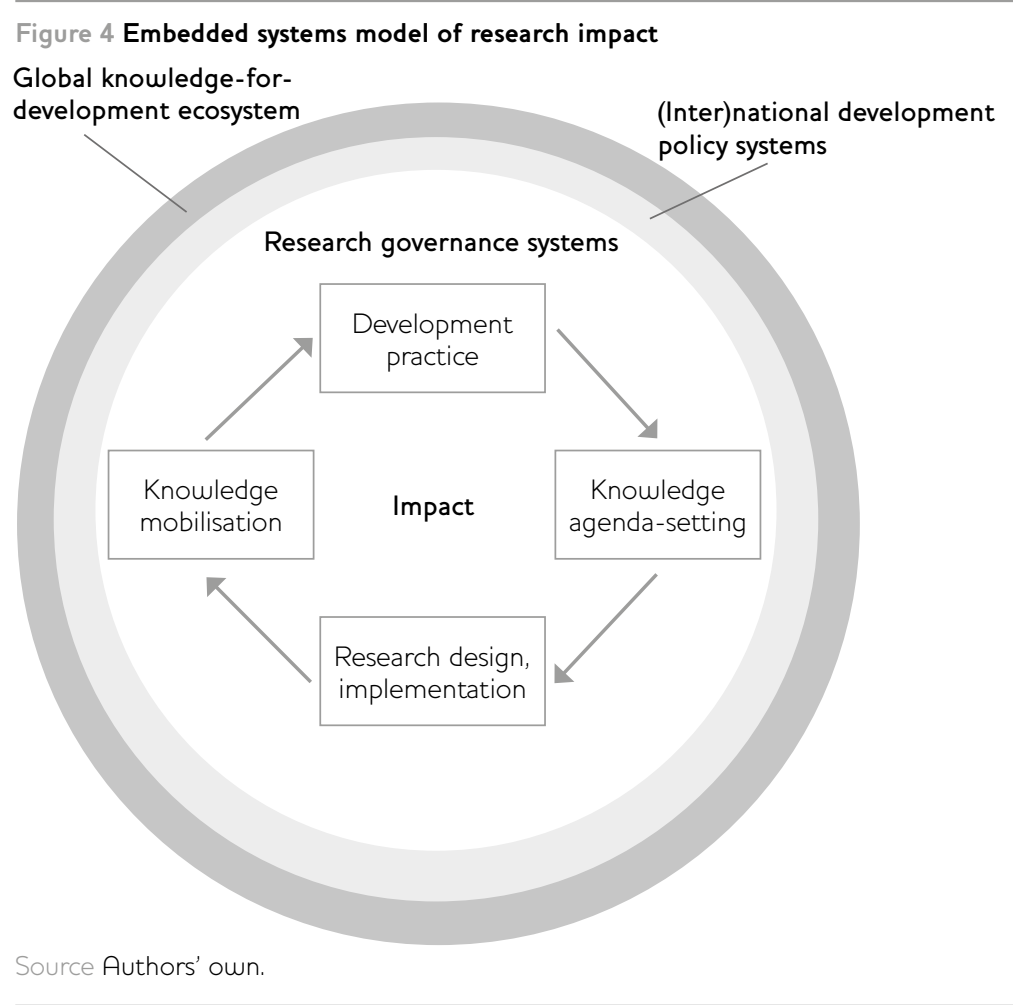


In the first three models, the focus is on the academic research system, which might or might not invite collaboration from non-academics. In contrast, the knowledge mobilisation cycle at the heart of Figure 4 invites academic research processes to engage with the ongoing knowledge activities of development practitioners (see Hayman et al. 2016; Mougeot 2017), while recognising the effects of the broader national and international knowledge systems in which the cycle is embedded (Bradley 2017; Kok et al. 2017; Lebel and McLean 2018; UKCDS 2017).

We argue that this fourth type of approach is necessary both to fulfil the ambitions of ODA compliance in research impact; and to adhere to the implications of the eight principles developed for fair and equitable research partnerships. This has implications for how research impact is conceived and understood; as well as how such impact can be created.

We suggest that the principles, initially developed to support the process of fair and equitable research partnering, can (and indeed should) be applied to give meaning to the concept of research impact. Reflecting on the principles enables us to develop a deeper understanding of the potential for research impact, and how it might be achieved. Responding to these insights suggests a need for different types of relationships between UK-based academics and their research partners; which in turn can enable a more diverse, inclusive, and relevant approach to the production of development knowledge.

\section{Eight principles for fair and equitable research partnerships 3.1 Background and methodology}

In early 2018, UK Research and Innovation (UKRI - a body set up to coordinate work across the seven research councils, Innovate UK, and Research England, and to create an environment to enable research and innovation to flourish) was considering how to strengthen the ODA commitments of the GCRF in response to some criticism from the Independent Commission for Aid Impact (ICAI 2017). 'Fair and equitable' research partnerships were a key element of the GCRF's approach to delivering these commitments (UKCDS 2017), but there was limited shared understanding of what the idea of 'fair and equitable' research partnerships meant in practice.

In response, the RRC proposed some strategic research (involving the collection of qualitative data through interviews, focus group discussions, and written statements) to explore the perspectives and experiences of research 'partners' (i.e. those individuals, organisations, and networks who were not based in UK academic institutions, but had been, or had the potential to be involved in ODA-funded research; these included INGO and research broker organisation staff based in the UK, and academics and civil society based in the global South ${ }^{7}$ ). Over a one-month period, the RRC reached out to its extensive networks, with each of the co-investigators targeting partners from their own stakeholder group. Respondents reflected on their experiences as partners in research, focusing on the factors which enabled and constrained their participation. It quickly became clear that in 
considering fair and equitable research partnerships, it is not enough to look at a specific partnership in isolation; rather, it is necessary to consider the entire research system - from agenda-setting, to research design, implementation, and communication, as well as the mobilisation of knowledge into practice and policy beyond the research.

Building from the research, we held a roundtable event in April, bringing together key representatives from UK-based research funding bodies, GCRF strategic research leads, and representatives from the different partner organisations to discuss our findings. We also carried out a literature review to examine existing resources on partnerships. The research and discussions led to the development of a set of principles for fair and equitable research partnerships and a set of resource materials, ${ }^{8}$ targeted at different stakeholder groups, to support translation of these principles into policy and practice.

\subsection{Eight principles}

The eight principles identified are as follows:

1 Put poverty first.

2 Critically engage with contexts.

3 Redress evidence hierarchies.

4 Adapt and respond.

5 Respect diversity.

6 Commit to transparency.

7 Invest in the relationship.

8 Keep learning.

In the following section, we take each principle in turn, and consider its implications for a renewed understanding of research impact. We introduce the principle through a quote from a 'research partner' (collected during our research) which influenced the formation of the principle. We then unpack the meaning of the principle, drawing on an example from practice to identify the implications for an embedded, systems-based approach to research impact.

\subsection{Applying the principles to a renewed understanding of research impact} Principle 1: Put poverty first (Kate, Christian $\mathrm{Aid}^{9}$ )

Research becomes meaningful only when it helps the communities... it is extremely important to reflect on what constructive purpose the research is serving in light of the larger societal context and how it is contributing in making the world a better place to live. (Academic based in the global South ${ }^{10}$ )

For CSOs which are campaigning for social justice or implementing poverty eradication programmes, the need to 'put poverty first' is clear. 
Poverty eradication is our core mandate and research is only meaningful if it adds value to our interventions, integrates with our wider work plans, and contributes to our organisational objectives. More generally, as practitioners we spend a lot of time thinking about what success looks like in our work, and what this means for how impact is understood, what it might look like in different settings and how it is created considerations such as this are bound up in our day-to-day practice. The need to unpack assumptions about impact were highlighted to me in a specific experience I had last year:

It's 2017, I'm sitting in an Arts and Humanities Research Council moderators panel which is grappling with the challenge of which proposals to fund; and I am reflecting on the notion of impact. Many of these research projects are giving primacy to the power of the arts to enable developmental impact. But I'm not so sure. At their heart, these are research projects, aimed at developing new knowledge. Assumptions that knowledge will translate into action and new behaviours permeate the 'impact pathways'. And yet, I know from my work in INGOs that there is no simple linear link between knowledge and behaviour change. As I listen to the principal investigators describe their work and plans, I'm asking myself what assumptions are being made here; which of these research projects will have developmental impact. Is it about the methodologies they use, or the relationships that they have that will enable them to contribute to positive change? How much do these researchers know about other development interventions that are happening in the same area, and the challenges and successes they have had in bringing about change? Does the literature review include analysis of practitioner-generated literature detailing reflections on their learning around behaviour change, or is the focus just on how the research is located within the current academic body of knowledge? (Kate Newman)

Reflecting on this experience suggests that if research is to have realworld impact, then it is not enough to articulate a research question that appears to address a development challenge; it is not even enough to design a good participatory process, which involves those who are facing the particular development challenge in question. Rather, it is important to locate the research within a wider practice-based theory of change - and to understand how it will 'land' in the broader context. Those designing the research need to have a deep understanding of the actors, processes, and interventions already at play, and of the different dimensions and paces of change; to understand how their research integrates into ongoing work.

Attention to these issues influences the research questions and who is asking them; the research design and whose voices are included; the research process and who the researchers are; and how creating impact will be considered and actively sought through the process. But beyond this, it suggests a shift at every level of the research system - including rethinking how research agendas are set, and how incentives are integrated into the system. For example, research funders would need to consider how to encourage and enable discussions to take place, so that those involved in supporting practical development work are able to 
become influential in how research is framed, planned, and implemented, ultimately to create the best possibility for impact throughout.

\section{Principle 2: Critically engage with contexts (Kate, Christian Aid)} If the [UKRI] could foster genuine research collaborations over the medium to long term through its funding modalities, this would offer transformative potential for research. To make this possible, [UKRI] needs to consider the way the entire research funding pipeline is structured and how research collaboration can be strengthened at each point. (Civil society practitioner based in the global South)

To understand and respond to the complex pathways to development impact discussed through the previous principle, it is crucial to recognise the multiple contexts of impact, mapping the different actors involved and identifying opportunities and barriers for change. Where we are located, what we prioritise, and how we respond to different types of evidence and knowledge, influences how we frame and understand issues. Researchers should be constantly questioning the representativeness of their partnership and the broader research funding and policy systems that support them, asking: who is included, and are they the best placed to understand and respond to the development challenges in question, or are they involved because they are relatively easy to reach and well connected? Development brokers such as large INGOs are well placed to understand and mediate these different contexts.

Based in the UK office of an INGO, I have the opportunity to interact with multiple contexts - on one day I might speak to a UK-based academic or someone from a funding institution; and my colleagues in our country offices. Having relationships across these different contexts allows me to understand some of the different dynamics, pressures, incentives and interests at play, and negotiate between them, often acting as a broker when sitting in my office in London, but equally relying heavily on my colleagues, and their ability to 'translate' contexts, when I visit a programme in the global South.

Switching between contexts helps me to understand what I know, but equally what I don't know. Christian Aid understands poverty as being caused and sustained by unequal power relations; recognising that the way these are experienced differs in different settings, and for different people (and groups of people). Through working closely with our country programmes we come to understand their contextual experiences, and create spaces so that they can determine how and why to enter into global debates. I listen, learn, and adapt my thinking; but also share my understanding of my local context so that I can support others to participate in it. By working together we aim to influence and challenge the norms that are in operation; to shift global power dynamics that shape how we interact, and how our knowledge, experiences, and perspectives are responded to. (Kate Newman)

Although contexts shape the possibilities for partnership, and for research, no context is fixed, they are dynamic. In mapping and 
exploring different aspects of the context - considering who the actors are, what motivations they have, their evidence preferences, and what opportunities and constraints these present, as well as what 'power' means (i.e. who has it, why, and how is it used) - we can start to appreciate the different dynamics which shape research and influence its potential for impact. This can lay the foundations for pragmatic decisions on the extent to which such dynamics are confronted through the research and the partnership, worked around, or merely acknowledged in our research approach and impact planning. More fundamentally, this suggests that a rooted power and political analysis needs to be at the heart of a research-for-impact process, suggesting the importance of recognising diverse skills within any research process (see Principle 5).

\section{Principle 3: Redress evidence hierarchies (Sowmyaa, Praxis)}

Leadership should not be determined merely by geography or history, but by the capabilities and experience of those involved. Researchers in the global South should not be constantly put in the position of providing data for those in the $U K$ to analyse and publish. (Civil society practitioner based in the global South)

Whose knowledge is valued, and who participates in the different stages of the research process - from design through data collection, to analysis and publication - are all underpinned by expectations about what constitutes 'quality evidence'. Although it is clear that different types of evidence are relevant when responding to different research questions, it is also clear that for many Southern academics and practitioners, there are unspoken hierarchies of evidence which marginalise their knowledge and experiences and may confine them to the role of data collectors. Reflecting on how these hierarchies play out has wider implications for impact.

Being put in the position of providing data for Northern academics to analyse and publish is an issue I have encountered frequently. It comes about largely because of the way that knowledge and evidence currently come to be seen as 'legitimate'. There is a well-established and rather non-dynamic route for research making its way into peer-reviewed journals and there are standards and processes in place to ensure whether a methodology is ethical or not. Those who manage to manoeuvre their way along these pathways tend to belong to a certain powerful class. Academic qualifications - especially PhDs - are a barrier to entering this pool of people as such qualifications are valued over years of lived experience, even if that experience has contributed to deep knowledge on the subject of the research.

A striking characteristic of current evidence hierarchies is that knowledge created by communities and their NGO partners is marginalised as grey literature. We struggle to carve out space for community outputs as valid evidence; our experience is that these are often modified by researchers who use complex frameworks to which people's realities are retrofitted. Northern researchers add this layer of interpretation to research findings to make them 'acceptable'. 
And in this process, the communities or $N G O$ s that generated evidence in the first place remain relegated to the position of information sources. The provision of a token space for the marginalised to 'participate' in research is almost always just enough to acknowledge the need to be 'democratic and informed', whilst ensuring that the balance of power remains undisturbed. (Sowmyaa Bharadwaj)

While impact in relation to Principles 1 and 2 concerned real-life changes in poverty contexts, impact here relates to the types of knowledge that are considered valuable in international development, and how knowledge is mobilised within the wider system. To have an impact on poverty, we need to include a wider diversity of knowledge to drive research agendas. This does not mean that diversity of knowledge is appropriate in every research setting. For example, scientific or medical research often includes specialist expertise and decontextualised knowledge; even so, how it translates into practice depends on broader social understanding. But in considering the impact of social science research, the needs, aspirations, and visions of those living in poverty are of central importance, suggesting a need to develop systems to enable diverse forms of knowledge to influence locally, nationally, and globally.

This means that we need to revisit systems that classify different types of evidence and shape the distinction between 'grey literature' and valid (academic) evidence and knowledge. Key to this is to build more democratic systems of knowledge certification, to decentralise control over peer-reviewed journals and other mechanisms that widen chasms, and to invest in processes to encourage and enable different types of evidence to flow into international development knowledge. For example, through involving non-academics more in research agendasetting and allowing them to take on leadership roles. This will ensure that the knowledge generated from any research is deeper, shared on its own terms with its own framing, voices, and positionality, more closely aligned with the multiple and complex processes of change, and thereby more able to create impact.

\section{Principle 4: Adapt and respond (Kate, Christian Aid)}

Unnecessary controls in the process need to be done away with. There should be an option for an optimum degree of flexibility in the process, and more importantly, space for creativity and innovation... This is because we in the South can see certain things which others cannot see, and therefore, we should have enough liberty and freedom to change course, when necessary. (Academic based in the global South)

Social change is complex and complicated, and rarely follows a linear planned path. Although there is continued pressure from funders and policymakers for those implementing development programmes to clearly identify project outcomes, and follow neatly designed programmes of activity to reach these, there is also recognition that such pathways do not exist. Whether intended activities create the intended impact depends on the individuals involved, the (shifting) context, and broader socioeconomic, political, and environmental 
dynamics. More progressive development funders are increasingly open to funding interventions that specify a programme objective, but enable flexibility in how that objective is reached, valuing space to reflect, learn, and adapt as programmes are delivered. Much can be learnt from the long-term and relational practices of NGOs which have a deep, engrained understanding of the contexts in which they work, and are adept at responding and adapting practice accordingly.

I am travelling to Colombia to set up a ten-year study as part of Christian Aid's commitment to deepen our understanding of how change happens, and how we and our partners contribute to it. Before I travel, I have had a few conversations about the study with my colleagues in Christian Aid Colombia, discussing the context (including the recent signing of a peace accord following over 50 years of armed conflict) and their work. But I have not had a chance to meet the partner organisation (Cómision Intereclesial de Justicia y Paz) yet. I arrive in Bogotà, and then we travel to a rural area which will be the site of the study. It is here that I intend to carry out focus group discussions with community members to understand their recent experiences, and how they view the concepts of justice and peace.

fust before I arrive, a human rights defender is killed. The community visits are dominated by memorials for the individual; people are sad and scared. I have travelled a long way and used precious resources to set up this study, and yet I realise the timing is not right to assert my research needs. I must find other ways to engage, to adapt my plans, and integrate with the current needs of the community participants and the local partner. I need to listen and respond to the possibilities presented, keeping an eye on what I was trying to achieve, while respecting the needs and priorities of others involved. Less time is spent on the research itself, and more on clarifying what the partners and community want and need, and how the research would integrate with their ongoing plans to challenge injustice and build peace. It becomes clear that the research itself is seen as a way of documenting community memory; and that the international visibility which would come through the research is part of a wider plan to enable those affected by the conflict to rebuild their lives of dignity to become agents of change and build sustainable peace; my understanding of impact shifts dramatically. (Kate Newman)

Real-world research can be challenging - the 'study area' interacts with an ongoing process, it is not a test location or a bounded discrete entity or experience. This can make planning and implementing research complex. Taking a responsive and adaptive approach can enable research to embed more deeply in its context and unearth greater possibilities for impact. Social change strategies often include processes of horizon scanning and adapting to shifting contexts and opportunities. This also implies that pathways to impact should have inbuilt flexibility to evolve over time and must be revisited, collectively, throughout the research partnership. The ability to do this will depend on strong partnership relationships with clarity of vision for the research, alongside deep understanding of the dynamic context in which it is taking place. 


\section{Principle 5: Respect diversity of knowledge and skills (Sowmyaa, Praxis)}

Creative and participatory methods are best suited to engaging communities because they allow for different forms of knowledge to be recognised, and because they open the possibility for communities to make use of the research process, themselves. (Civil society practitioner based in the global South)

Making a research partnership greater than the sum of its parts means taking time at the outset to explore the knowledges, skills, and experiences that each partner brings; this includes recognising the full range of skills, beyond academic expertise, needed for partnership and for impact. Moreover, if that research is to create development impact, this will also involve exploring the views, perspectives, and aspirations of those whose lives the research is intended to change. It is not enough to understand skills, but also to consider the motivations and expectations of different partners, and each other's institutional contexts.

Being associated with an organisation that uses participatory methods and approaches to sustainable development, I find that participatory research has often emerged as a way of bringing in diverse perspectives. We are frequently approached to facilitate engagement with marginalised groups to bring their voices to the fore and often this engagement is at the core of the research output. Divergent views within the various community groups, between the researchers and the researched as well as among the various sets of researchers, emerge. The struggle is to navigate the complexities of these diverse views and at the same time, do justice to the processes that facilitated the articulation of these views. (Sowmyaa Bharadwaj)

While researchers are good at research, they may be less capable of creating change strategies, or reading and responding to opportunities to bring about change and impact, than the group of people for whom the impact is intended. Those living in poverty and experiencing discrimination and marginalisation on the other hand, when provided appropriate opportunities, are very capable of designing strategies that have far-reaching and meaningful impact. Thus, researchers need to ensure that such diverse individuals' skills are valued and respected as a foundation to creating impact.

The way that change and impact are understood and prioritised as well as understanding what types of change may be most impactful (for example, is it about those involved acting on new knowledge, or about policy change, or theoretical understanding?) requires a concerted effort. In order to create impact, we therefore need to create space to consider different perspectives on, understandings of, and needs for impact; and value diverse and distinct pathways for the importance they hold for different members of the partnership. 


\section{Principle 6: Commit to transparency (Sowmyaa, Praxis)}

The entire grant process should be carried out in a structured, organised, and transparent manner. Aspects like budget and funds disbursal should be free from ambiguities to avoid any conflicts later on. There should also be flexibility in how and where the money flows, to avoid any stakeholder exerting undue rights over research funds. (Academic based in Asia)

A code of conduct or a memorandum of understanding are useful ways to make explicit the commitments of each partner in a research partnership. These include administration and budgeting, and the rights of all partners regarding acknowledgement, authorship, intellectual property, and data use. But despite the possibilities offered by mechanisms like these, there are underlying challenges about the meaning of transparency.

When I was interviewing practitioners in the global South for this research, several noted that while Northern partners tended to be very transparent about working out the research design, methods, and plans, when it came to budgets and finances, 'transparency' looked different. Southern practitioners shared how they were often expected to submit their cost estimations with no yardstick to measure against, and then these were beaten down so that they ended up working for a fraction of overall costs; after multiple iterations on methods and rushed submissions, no one had time for transparency in budgetary discussions. Similarly, at the other end of the research process, Northern partners determined which information about the research was relevant to share in monitoring reports to donors, almost always lacking overall financial reporting.

\section{In Praxis we have had similar struggles, and have learnt that transparency} needs to be about the relationships rather than a legal document. For example, when agreeing copyright there is often a long complex exchange with the legal department of the contracting entity. We might be assured of flexibility, but when the work is complete and we seek 'permission' to use the data that we have collected, we are politely refused. Rather than engage in a debate about copyright itself, we are referred to the copyright clause that was signed off on in the contract. It's almost as if transparency is wholeheartedly encouraged by the more powerful and those controlling the finances - and they put in several clauses that showcase transparency, but because they have access to systems they can ensure that they seem benevolent while power hierarchies remain in the status quo. (Sowmyaa Bharadwaj)

Challenges to transparency affect the wider processes surrounding research - including who feels ownership of the process, which can limit the potential for impact. Partners in a research relationship, in embracing the commitment to transparency, should ensure that they find ways to recognise and question these inbuilt power hierarchies rather than perpetuating them. It is only by considering the wider relationship and behaviours that transparency can begin to operate as a value rather than a transaction. In this way, it can contribute to creating impact within the specific partnership relationship and related research, and beyond to the wider research system, to open up space for discussions on fairness and equity, and to consider how impact is attributed and owned. 


\section{Principle 7: Invest in the relationship (Sowmyaa, Praxis)}

The level of effort and time to bring the researcher team together with the implementing team to speak similar language, to understand each other, is exhausting. All additional costs have to be covered, and the practitioners have to be fully involved in conceptualisation, design, methods development, etc. So having a model where your costs are capped or you are even expected to contribute your own resources doesn't work. (INGO practitioner, global North)

Partnership working takes time, and this needs additional investment beyond the costs of the research itself. Ensuring that relationships between partners move beyond the transactional relationships detailed in the contract can offer better opportunities for impact. But creating space for communicating, listening, and understanding multiple perspectives within a research partnership is not always straightforward.

For us at Praxis, research relationships that have gone beyond a contract relationship have been far more enjoyable, offer a much better space for innovation, have yielded far better results and been used in forums and platforms that were not initially planned. The stumbling block to such relationships is sustainability, because the relationship with an organisation is invariably steered by an individual. Organisational relationships are actually those of two people; a lot depends on this.

Another often tricky side to relationship building is ensuring recognition of the different levels of power that the partners in the research relationship wield. Often, in tripartite relationships with Northern academics that we align with in philosophy, we feel pushed up against a wall if one of the other consortium partners who we are depending on for their visibility potential, like for instance a government department, happens to be an agency that perpetuates or strengthens power hierarchies itself. The challenge then is to work out whether to invest in strengthening such a relationship. (Sowmyaa Bharadwaj)

Strong and sustained relationships are vital for impact, but relationship building is a less tangible aspect of research and seldom funded. And yet, sustained relationships are essential for bridging knowledges, creating common languages, and facilitating impact pathways. Funders could help by earmarking funds for the relationship before, during, and after projects. Partners might also consider the need to work beyond the templated and inflexible contractual dotted line framework and join efforts. This would help to avoid reducing partnerships to the commitments of individual people, by investing in strategies to ensure that the wider organisation benefits from, and has an interest in, sustaining the partnership. Given the long timescale of development impact, such long-lasting relationships are key to enabling sustainable change.

\section{Principle 8: Keep learning (Jude, Open University)}

[The lead partner] organised monthly reflection meetings and quarterly planning meetings where partners shared the work and challenges. This helped inform the shared decision-making system. (Civil society practitioner based in Asia) 
Research partnerships are important because they enable us to work with people that we would not usually work with, and in ways that we do not usually work. This can give us access to new skills, perspectives, understandings, and knowledges; and it can mean that together we can create opportunities for synergies and deeper understandings. Learning is about mindset and openness. Within a research partnership, it is about valuing diversity. If the partnership is to become a site for transformation, it is necessary to deliberately create spaces to enable learning. It is also important to recognise that learning is not always comfortable and can frequently be emotional - while on the one hand we might be learning new skills, we might also be learning about ourselves, our assumptions, and behaviour. Translating that learning into action requires bravery and honesty. Without mechanisms to capture learning and channel it back into onward organisational strategies, the benefits of individual and collective learning will always be limited.

Our strategic research was grounded in previous learning - from within our different organisations, through our emerging collective RRC network, and that of the wider community of people involved with the GCRF. While our objectives emphasised the creation of learning outputs, I underestimated the extent to which the project would spark learning on an individual level and for our collaborative. The rushed and under-funded nature of the work meant that partners were giving far more than their paid time. Feelings of frustration, indignation, and even resentment merged with high levels of stress. But there were positive emotions too - a passionate commitment to our vision for changing policy and practice, shared moments of solidarity and humour, exhilaration when it started coming together and the funders responded so positively.

Uniting at the end of the project to write a reflexive learning case study allowed us to vent and share these emotions and experiences. We had all experienced different learning journeys and had been affected in different ways but creating a space to express these enabled us to build trust and feel stronger as a team. Developing this article has been a similar challenge but also another opportunity to listen to and learn from each other. However, we are still challenged in how best to channel this learning beyond the individual partners back to our own institutions and the project funders. With so much emphasis on 'success' and pressure to showcase achievements, it is hard to have deep discussion at the institutional level, to engage with wider systems, and encourage them to respond to the more uncomfortable aspects of learning. (Jude Fransman)

A meaningful model of impact for ODA-funded research must have learning at its core. Learning underpins ability to: develop shared understandings of context and agendas for change; map and respond to different actors; unpack power and bring together different knowledges and experiences; flexibly adapt to changing circumstances; and ensure strong communication and ongoing relationships. Moreover, spaces for individual reflection must be complemented with processes to share learning, within the partnership and beyond, to translate learning into organisational development. Taking a learning approach requires a 
Table 1 Contribution of the eight principles to a renewed understanding of impact/towards a process of achieving greater impact

1 Put poverty first Situate research impact pathways within existing practice-based development work/impact systems

2 Critically engage with contexts

Consider the multiple contexts of research and who is represented across the partnership and research system, reflecting on implications for how impact is understood, where impact might be felt and given meaning.

3 Redress evidence hierarchies

Recognise the different knowledge and evidence preferences/needs of the actors involved and ensure spaces are created to shift assumptions on what types of evidence, and whose knowledge can create impact and how.

4 Adapt and respond

Complex and rapidly changing development contexts require responsive and adaptive practice. Learn from the vast experience of practitioners who work adaptively and over the long term in specific contexts.

5 Respect diversity

Bringing together the diverse actors required for meaningful impact means valuing difference. Participatory and creative methods can help partners to understand each other and negotiate differences.

6 Commit to transparency To build trust and ensure the commitment needed to maximise impact, all processes (including budgets) must be open. Create impact in the research system to ensure transparency moves beyond legal agreements to influence behaviours, expectations and ways of relating.

7 Invest in the relationship To achieve meaningful impact, relationships must be strong and sustained. This involves thinking about shared visions and agendas beyond the individual project and funding adequate time to understand each other and build trust.

8 Keep learning

To develop shared agendas for change and be able to create impact, invest time in individual reflection and ensure processes to feed learning back into the wider partnership and research systems.

Source Authors' own.

culture shift to recognising and embracing the learning from potential failure, acknowledging that while projects might struggle in certain ways, learning from this can be key to enabling impact. This includes a recognition that impact may come in a different form from that initially envisaged.

Table 1 summarises the contribution made by each of the principles to our proposed understanding of impact. 


\section{Conclusions}

By reflecting on and giving meaning to a set of principles, initially designed to support 'fair and equitable partnerships', we can delve deeper into understanding the role partnerships can play in contributing to more impactful research. Our experience and our analysis suggest that there are multiple factors that need to be considered if research is to become properly embedded in systems of development and change.

Theory on research impact has evolved in recent years. What started with assumptions of linear transfers - linking knowledge and impact directly - have become more complex, recognising both the need for co-production during research processes and considerations of cyclical models of research uptake, adaptation, and use. However, to date, this theory has engaged with impact from the perspective of the academic research system. By drawing on the eight principles for fair and equitable partnerships, generated from a 'partners' perspective', and sharing specific experiences we argue that if research is to be truly impactful, it needs to take its direction from the ongoing development activities of those working actively to bring about social change. By taking practice as the starting point, and appreciating the complex pathways to creating change, it is more likely that research will be able to contribute to real-world impact. This shifts the way research impact is understood, to ensure that it responds more closely to the knowledge and experience of those working directly to challenge poverty and contribute to social justice.

Operationalising such an embedded approach to impact has implications at different levels, for different actors involved.

Academics based in the global North need to be properly incentivised and supported to develop deeper impact models. This includes establishing the skills and capabilities they need to be able to properly engage with the understanding, knowledge, and experience of those outside the Northern university environment. It also means ensuring that a process which encourages the reporting of impact also takes into account the complexity of pathways, and focuses on valuing contribution rather than attribution, recognising the range of dynamics that affect the potential of any piece of research to create impact. Likewise, academics in the global South need to be encouraged to identify where collaboration with Northern-based academics brings value, and where collaboration with civil society practitioners may be more appropriate.

Understanding impact as complex, multifaceted, adaptive, cyclical, and long term has implications for research governance and agendasetting. Research funders in the global North will need to develop new funding models with greater representation of a diversity of development actors in funding decision-making. New investment must be made to ensure adequate time for mapping impact contexts and actors, to respond to complex development impact pathways, and to 
build strong, open relationships which recognise and combine different knowledges, creating spaces and systems for learning throughout.

Finally, civil society practitioners based in the global North and South also need to adapt: this includes recognising and asserting the skills and understanding that they have developed through their development interventions and applying these in the field of development research. But it also requires a deeper understanding of what research can and cannot bring into their wider impact strategies. Such practitioners need to understand when research might be useful, what research might be useful, and what skills and relationships are needed to be able to do it.

There are many good reasons for practitioners to engage in research as part of their development interventions; for example:

To understand more about an issue observed as affecting programming and thereby to sharpen a programmatic intervention/ building a better response to a development challenge;

To deepen understanding or gather evidence on an issue which may inform policy development, or be used within advocacy and campaigning action;

To support reflection on and development of internal organisational practice, including how knowledge and evidence are understood within the organisation;

To capture learning and deepen understanding of how work contributes to change, to strengthen practice, to secure funding, or influence the practice of others; and

As a way of exploring, articulating, gathering, and documenting, from the perspective of those involved in programme work, to enable their voices, understanding, and sense-making to inform wider debates and dialogue on specific development issues.

But for research to have impact in any of these cases, it is crucial that the practitioner situates the research within their broader change strategy and invites others to collaborate within their process. This requires that all those involved acknowledge their skills and capabilities, positionalities, and motivations, to work together to enable such responsive embedded research, being honest about both the potential and limitations it offers. By building research agendas and focusing research design in this way, those involved in scoping, funding, and delivering ODA-funded research can create the potential for ODA excellence and enable research to play an active role in poverty eradication. 


\section{Notes}

* This issue grew out of the Impact Initiative for International

Development Research which seeks to maximise impact and learning from ESRC-DFID's Joint Fund for Poverty Alleviation Research and their Raising Learning Outcomes in Education Systems Research Programme.

+ The authors would like to thank our funders, UK Research and Innovation (UKRI) for supporting this work. The research was supported by the Global Challenges Research Fund (GCRF), grant number: NS/A000075/1 and also by a Leverhulme Early Career Fellowship which allowed the Principal Investigator (PI) to coordinate this work, grant number: ECF-2014-605.

1 Christian Aid, UK.

2 Praxis Institute for Participatory Practices, India.

3 The Open University, UK.

4 The authors would like to thank the co-investigating team who have been an integral part of the thinking in this article: Budd Hall, Rachel Hayman, Pradeep Narayanan, and Rajesh Tandon.

5 www.oecd.org/dac/financing-sustainable-development/ development-finance-standards/What-is-ODA.pdf.

6 www.ukri.org/files/legacy/international/gcrfodaguidance-pdf/.

7 Some of these partners had been actively involved in GCRF or UK-funded research, others were potential partners; we wanted to understand why they had not been involved to date.

8 See www.christianaid.org.uk/about-us/programme-policy-practice/ resources-fair-and-equitable-development-research-partnerships.

9 The name in brackets beside each principle refers to which of the three authors is reflecting on their practice in addressing this principle.

10 This and following quotes from interviews/focus group discussions, April 2018.

\section{References}

Bardsley, C. (2017) 'The Pursuit of Impact through Excellence: The Value of Social Science for Development, A Funder's Perspective', in J. Georgalakis, N. Jessani, R. Oronje and B. Ramalingam (eds), The Social Realities of Knowledge for Development: Sharing Lessons of Improving Development Processes with Evidence, Brighton: IDS/Impact Initiative

Beckett, K.; Farr, M.; Kothari, A.; Wye, L. and le May, A. (2018) 'Embracing Complexity and Uncertainty to Create Impact: Exploring the Processes and Transformative Potential of Co-Produced Research through Development of a Social Impact Model', Health Research Policy and Systems 16.1: 118

Boswell, C. and Smith, K. (2017) 'Rethinking Policy "Impact": Four Models of Research-Policy Relations', Palgrave Communications 3: 44, https://doi.org/10.1057/s41599-017-0042-z (accessed 21 February 2019)

Bradley, M. (2017) 'Whose Agenda? Power, Policies, and Priorities in North-South Research Partnerships', in L.J.A. Mougeot (ed.), Putting Knowledge to Work: Collaborating, Influencing and Learning for International 
Development, Ottawa ON: International Development Research Centre (IDRG)

Cairney, P. and Oliver, K. (2018) 'How Should Academics Engage in Policymaking to Achieve Impact?', Political Studies Review, https://doi.org/10.1177\%2F1478929918807714 (accessed 21 February 2019)

Carbonnier, G. and Kontinen, T. (2014) North-South Research Partnerships: Academia Meets Development?, EADI Policy Paper Series, Bonn: European Association of Development Research and Training Institutes

Conway, G. and Waage, J. (2010) Why Science Is Important for Innovation, Development Outreach, Washington DC: World Bank, https://openknowledge.worldbank.org/handle/10986/6063 (accessed 21 February 2019)

Datta, A. (2012) 'Deliberation, Dialogue and Debate: Why Researchers Need to Engage with Others to Address Complex Issues', IDS Bulletin 43.5: 9-16, http://dx.doi.org/10.1111/j.1759-5436.2012.00357.x (accessed 21 February 2019)

DFID (2016) Research Review, London: Department for International Development, https://tinyurl.com/y9p7s8v7 (accessed 21 February 2019)

Dunlop, C.A. (2018) 'The Political Economy of Politics and International Studies Impact: REF2014 Case Analysis', British Politics 13.3: $270-94$

Fransman, J. (2018) 'Charting a Course to an Emerging Field of "Research Engagement Studies": A Conceptual Metasynthesis', Research for All 2.2: 185-229

Fransman, J. and Newman, K. (forthcoming) 'Rethinking Research Partnerships: Evidence and the Politics of Participation in Academic-INGO Research Partnerships for International Development', Fournal of International Development (advance online publication)

Georgalakis, J.; Jessani, N.; Oronje, R. and Ramalingam, B. (eds), The Social Realities of Knowledge for Development: Sharing Lessons of Improving Development Processes with Evidence, Brighton: IDS/Impact Initiative

Green, D. (2016) How Change Happens, Oxford: Oxford University Press

Hayman, R.; King, S.; Kontinen, T. and Narayanaswamy, L. (eds) (2016) Negotiating Knowledge: Evidence and Experience in Development NGOs, Rugby: Practical Action Publishing

HEFCE (2017) Research is all About Impact, Higher Education Funding Council for England blog, https://tinyurl.com/y6juh35y (accessed 21 February 2019)

HEFCE (2011) Decisions on Assessing Research Impact, Higher Education Funding Council for England, www.ref.ac.uk/2014/media/ref/ content/pub/decisionsonassessingresearchimpact/01_11.pdf (accessed 21 February 2019)

ICAI (2017) Global Challenges Research Fund: A Rapid Review, London: Independent Commission for Aid Impact, https://tinyurl.com/y8nlc883 (accessed 21 February 2019) 
Kok, M.A.; Gyapong, J.O.; Wolffers, I.; Ofori-Adjei, D. and Ruitenberg, E.J. (2017) 'Towards Fair and Effective North-South Collaboration: Realising a Programme for Demand-Driven and Locally Led Research', Health Research Policy Systems 15: 96

Lebel, J. and McLean, R. (2018) 'A Better Measure of Research from the Global South', Nature 559.7712: 23-26

Leege, D.M. and McMillan, D.E. (2016) 'Building More Robust NGOUniversity Partnerships in Development: Lessons Learned from Catholic Relief Services', Journal of Poverty Alleviation and International Development 7.2: 68-119

Mougeot, L.J.A. (ed.) (2017) Putting Knowledge to Work, Rugby: Practical Action Publishing

Nesta/Alliance for Useful Evidence (2016) Using Research Evidence: A Practice Guide, London: Nesta

Nurse, P. (2015) Ensuring a Successful UK Research Endeavour: A Review of the UK Research Councils, London: Department for Business, Innovation and Skills

Ofir, Z.; Schwandt, T.; Duggan, C. and McLean, R. (2016) Research Quality Plus (RQ+): A Holistic Approach to Evaluating Research, Ottawa: International Development Research Centre

Oliver, K. and Boaz, A. (forthcoming, 2019) 'Transforming Evidence for Policy and Practice: What We Know Now and What We Want to Know Next', Palgrave Communications

Prainsack, B. (2018) 'On New and Old Intersections: From Interdisciplinarity to Joint Inquiry', keynote paper presented at the Science in Public 2018 Conference, University of Cardiff, 17-20 December, https://docs.wixstatic.com/ ugd/48bd50_66b801501d204ed3a123b84b947ac823.pdf (accessed 21 February 2019)

UKCDS (2017) Building Partnerships of Equals: The Role of Funders in Equitable and Effective International Development Collaborations, London: UK Collaborative on Development Science, https://tinyurl.com/y9x78rhf (accessed 21 February 2019) 